IZA DP No. 5304

An Empirical Study of the Relationships between CO2 Emissions, Economic Growth and Openness

Eunho Choi

Almas Heshmati

Yongsung Cho

November 2010 


\title{
An Empirical Study of the Relationships between CO2 Emissions, Economic Growth and Openness
}

\author{
Eunho Choi \\ Korea University
}

Almas Heshmati

Korea University

and IZA

\section{Yongsung Cho \\ Korea University}

\author{
Discussion Paper No. 5304 \\ November 2010 \\ IZA \\ P.O. Box 7240 \\ 53072 Bonn \\ Germany
}

Phone: +49-228-3894-0

Fax: +49-228-3894-180

E-mail: iza@iza.org

Any opinions expressed here are those of the author(s) and not those of IZA. Research published in this series may include views on policy, but the institute itself takes no institutional policy positions.

The Institute for the Study of Labor (IZA) in Bonn is a local and virtual international research center and a place of communication between science, politics and business. IZA is an independent nonprofit organization supported by Deutsche Post Foundation. The center is associated with the University of Bonn and offers a stimulating research environment through its international network, workshops and conferences, data service, project support, research visits and doctoral program. IZA engages in (i) original and internationally competitive research in all fields of labor economics, (ii) development of policy concepts, and (iii) dissemination of research results and concepts to the interested public.

IZA Discussion Papers often represent preliminary work and are circulated to encourage discussion. Citation of such a paper should account for its provisional character. A revised version may be available directly from the author. 
IZA Discussion Paper No. 5304

November 2010

\section{ABSTRACT}

\section{An Empirical Study of the Relationships between $\mathrm{CO} 2$ Emissions, Economic Growth and Openness}

This paper investigates the existence of the environmental Kuznets curve (EKC) for carbon dioxide (CO2) emissions and its causal relationships with economic growth and openness by using time series data (1971-2006) from China (an emerging market), Korea (a newly industrialized country), and Japan (a developed country). The sample countries span a whole range of development stages from industrialized to newly industrialized and emerging market economies. The environmental consequences according to openness and economic growth do not show uniform results across the countries. Depending on the national characteristics, the estimated EKC show different temporal patterns. China shows an N-shaped curve while Japan has a U-shaped curve. Such dissimilarities are also found in the relationship between CO2 emissions and openness. In the case of Korea and Japan it represents an inverted Ushaped curve, while China shows a U-shaped curve. We also analyze the dynamic relationships between the variables by adopting a vector auto regression or a vector error correction model. These models through the impulse response functions allow for analysis of the causal variable's influence on the dynamic response of emission variables and it adopts a variance decomposition to explain the magnitude of the forecast error variance determined by the shocks to each of the causal variables over time. Results show evidence of large heterogeneity among the countries and variables impacts.

JEL Classification: C32, F18, F43, N55, O13, Q56

Keywords: carbon dioxide (CO2), environmental Kuznets curve (EKC), economic growth, free trade, development

Corresponding author:

Almas Heshmati

Department of Food and Resource Economics

College of Life Sciences and Biotechnology

Korea University

East Building, Room 217

Anam-dong Seongbuk-gu

Seoul, 136-701

Korea

E-mail: heshmati@korea.ac.kr 


\section{Introduction}

Improvements in economic growth and welfare can affect the types of technological and financial opportunities used to avoid and manage environmental problems. In this situation, it is interesting to know whether economic growth and environmental preservation can coincide or not. In general, environmental goods and their quality are normally good, denoting that increased earnings from free trade would increase an individual's demand for higher environmental quality. In the early stage of economic development, a small portion of excess income is typically allocated for environmental problems, and thus, at this stage, the industrialization process is likely to be accompanied by environmental problems. When GDP per capita increases and exceeds a certain threshold, the level of pollution typically decreases. This combined effect can result in an inverted U-shaped relationship between GDP per capita and the level of pollution.

This inverted U-shaped relationship between GDP per capita and various indicators of pollution is referred to as the environmental Kuznets curve (EKC), which was introduced by Kuznets (1955). This hypothesis, which suggests a U-shaped or inverted U-shaped relationship between two variables, implies a non-linear relationship that is applicable to many areas. A number of studies have examined the environmental consequences of trade liberalization and economic growth in recent decades. Furthermore, the climate change phenomenon, which has been an important research topic in recent years, has been considered to be one of the most important consequences of the global energy system and use. Carbon dioxide (CO2) accounts for the largest portion of greenhouse gas emissions and is a major source of environmental problems. Thus, it is meaningful to examine the causal relationships between environmental pollution, trade liberalization, and economic growth.

By applying EKC theory, previous studies have provided a better understanding of the environmental consequences of international trade and suggested that economic growth can improve the environment and that economic growth is necessary for maintaining or improving the quality of the environment. However, most of the previous studies have not taken into account the different levels of income across countries. In this regard this study is an attempt to remedy this limitation by focusing on comparing the relationships between $\mathrm{CO} 2$, trade liberalization and economic growth by accounting for level of development.

According to the EKC concept, $\mathrm{CO} 2$ emissions are expected to have a positive relationship with the level of income or trade liberalization before the EKC threshold and then a negative relationship beyond the threshold. For example, if there is a negative relationship between $\mathrm{CO} 2$ emissions and free trade, then GHG emissions are likely to decrease as the country becomes more exposed to open markets. Similarly, if there is a positive relationship between $\mathrm{CO} 2$ emissions and free trade, then the country is not likely to have experienced its optimal level of trade liberalization. The EKC framework implies the existence of an inverted U-shaped relationship between GDP per capita and environmental degradation to be a local pollutant. However, the existence of the EKC for the global pollutant, for example carbon dioxide emissions resulting in problems of international scale, has not been agreed. There are different views relating to EKC. Galeotti et al. (2006) explained that empirical studies for the EKC hypothesis for CO2 emissions are "at best mixed". Even though we cannot find an 
EKC curve for $\mathrm{CO} 2$ emissions being evidence of sustainable development, we can find another way of sustainable development through international cooperation. Munasinghe (2008) suggested that the hypothesis of "sustainomics" can be the key to green growth and insisted that developing countries can achieve their target economic growth while maintaining a lower pollution level. Figure 1 illustrates the position of countries at different stages of their development on the EKC.

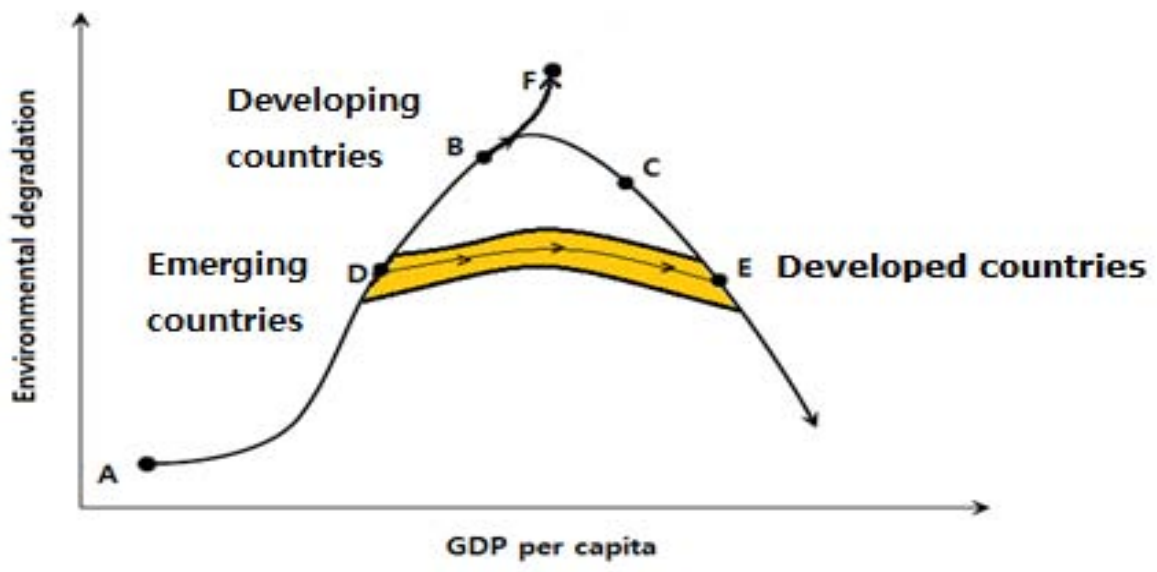

Figure 1: Tunneling through the EKC using international cooperation and sustainable policies.

Munasinghe (2008) insisted on the usefulness of the "tunnel effect", which may enable developing countries to attain their target economic growth while maintaining a lower level of pollution. Suppose that developing countries lie on Point B in Figure 1, then these countries can move to Point $\mathrm{C}$ by using clean technologies and developing and implementing sustainable development policies. Although it is difficult to facilitate the global pollutant to follow this pathway, we can expect a lower rate of increase than from point B to F. Further, if developed countries not only provide financial support to emerging markets and newly industrialized countries to help them cope with environmental degradation, but also transfer their environment-friendly technologies to those countries, the poorer countries may be able to shift from Point D to Point E, which is the basic concept behind the "tunnel".

The empirical results of this study are based on data from China, Korea and Japan. These countries, representing the Northeast Asian region, reflect different levels of economic development and have achieved considerable economic development. In addition to investigating the existence of EKC relationships, this study examines the dynamics relationships among three variables- $\mathrm{CO} 2$ emissions, openness, and GDP per capita - by using vector auto regression (VAR) and vector error correction model (VECM). These models, which use impulse response tests and variance decomposition functions, allow for the analysis of the interrelationships among various variables and enable the determination of the variables with stronger effects.

This study is unique in that it estimates the EKC by taking the evaluation and policy perspectives for an interesting sample of countries. The uniqueness of this study is that it estimates the environmental Kuznets curve, from evaluation and policy perspectives, 
for an interesting sample of countries. It focuses on the trend of $\mathrm{CO} 2$ emissions of each country and tries to analyze its relationships with openness and GDP per capita conditional on specific, growth, openness and other characteristics. Such a method allows for the positioning of countries on the EKC. The results indicating their position before and after the turning point have important implications for their growth and environmental policy.

Determining the existence of the $\mathrm{EKC}$ for $\mathrm{CO} 2$ as a global pollutant is important. If developed countries have an inverted U-shaped curve, it is likely that the global pollutant can be reduced through international cooperation and financial support. Therefore, this study focuses on the existence of the EKC for China, Korea, and Japan. Figure 1 illustrates the three countries' economic development levels and their positions on the EKC. Note that China, Korea, and Japan represent an emerging market, a newly industrialized country, and a developed country, respectively, which reflects the characteristics of the above hypothesis. The results of this case study have useful implications for developing and implementing appropriate policies for realizing the tunnel effect.

The rest of this paper is organized as follows. Section 2 provides a brief review of previous research on the EKC, and Section 3 presents the data. Sections 4 and 5 specify the relationships between environmental quality, economic growth, and openness by considering country characteristics and technologies. Section 6 presents the dynamic estimation results obtained using the VAR and VECM methods and the results of a number of tests that examined the properties of the data and model specifications, and Section 7 provides some appropriate policy recommendations based on the empirical results and concludes.

\section{The Literature on the Environmental Kuznets Curve}

An analysis of sustainable economic growth and development requires careful consideration of the environmental consequences of such development. Previous studies examining the nexus causal relationships between the environment, trade liberalization, and economic growth have stressed the need for further research in this area. We now provide a brief review of the growing body of literature investigating this topic. $^{2}$

Grossman and Krueger (1993) analyzed the relationship between environmental quality and GDP per capita by focusing on the level of urban air pollution to estimate the turning point for the atmospheric concentration of suspended particular matter (SPM) and sulfur dioxide (SO2). They proposed that air pollution can improve when GDP per capita increases to sufficient levels. They estimated the turning point to be $\$ 4,000 \sim 5,000$ (in 1985 U.S. dollars). This is the point at which people typically become concerned about the quality of their environment. If GDP per capita is approximately $\$ 10,000$, people may become involved in a number of activities to improve their environment, and thus, the quality of their environment is likely to improve considerably. Seldon and Song (1994) analyzed the relationship between income and air pollutants by using fixed and random effect models with panel data. In contrast to

2 The methodology has been extended to other types of causal relationships such as GDP growth, inequality and poverty (e.g. Heshmati, 2006). 
Grossman and Krueger's turning point (i.e., \$5,000 or less for SPM and SO2), their turning point for these pollutants is greater than $\$ 8,000$. They found that nitrogen oxides (NOx) and sulfur dioxide (SO2) have a Kuznets curve representing the existence of a relationship between national output and environmental quality.

Copeland and Taylor (1994) investigated the relationship between free trade and environment quality and suggested that free trade has three types of effects on countries. The first is the technology effect in which increases in income increase the consumption of environmental goods. Free trade induces people's interest in and understanding of environmental issues and people require effective pollution control and management policies. Thus, the technology effect through free trade is likely to improve the environment. The second is the scale effect. Free trade can lead to increases in world trade volume, and each country increases its output, which can in turn deteriorate the environment. The third is the composition effect. Developing countries tend to attract pollution-intensive industries, and developed countries are likely to avoid such industries to attract foreign direct investment. A decrease in pollution depends on the relative size of the technology and composition effects. Cole et al. (1997) investigated the relationship between GDP per capita and a wide range of indicators by using cross-country panel data and suggested that meaningful EKCs exist only for local pollutants. More global or indirect environmental effects tend to increase monotonically with income, which implies that it is easier to improve urban air pollution than to reduce national air pollution. They also suggested that concentrations of local pollutants tend to reach a turning point at a lower level of GDP per capita and that global air pollutants are likely to reach a turning point at a higher level of GDP per capita.

A noteworthy study by Moomaw and Unruh (1997) examined the relationship between $\mathrm{CO} 2$ and the level of income in developed countries. They selected 16 OECD member countries to investigate the EKC. Most of the countries showed an inverted U-shaped trend, and their turning point occurred between 1970 and 1980. Furthermore, by applying the cubic model specification to the 16 countries, they determined that the $\mathrm{N}$ shaped curves for all the estimated coefficients were statistically significant. The first and second threshold points were between $\$ 12,810$ and $\$ 18,330$. Friedl and Getzner's (2003) study showed that both linear and quadratic models were not suitable for analyzing the case of Austria but the cubic model can represent it more appropriately. The relationship between GDP and $\mathrm{CO} 2$ emissions followed an $\mathrm{N}$-shaped curve between 1960 and 1999. Galeotti and Lanza (2003) verified the inverted U-shape curve for the relationship between $\mathrm{CO} 2$ emissions and GDP.

Huang et al. (2008) considered economic development and greenhouse gas (GHG) emissions, which have been the focus of the Kyoto Protocol. The Protocol attempts to limit increases in GHG emissions among developed countries. They analyzed singlecountry time series and GDP data and found that most of the Annex II countries do not provide evidence supporting the EKC hypothesis. Akbostanci et al. (2009) investigated the relationship between income and environmental degradation in Turkey. By using a time series model spanning from 1968 to 2003, they found that CO2 emissions and income tend to have a monotonically increasing relationship in the long run. This monotonically increasing relationship implies that the EKC hypothesis does not hold in this case. Galeotti et al. (2009) explained that EKC is not found at all the times relating to $\mathrm{CO} 2$. Furthermore this paper makes a significant contribution to the statistical 
robustness of the EKC by giving a direction. The authors emphasize that theoretical and empirical investigation is clearly organized before the existence and validity of the EKC is established. The review of previous research indicates that there are substantial differences among the countries, suggesting that the hypothesis of the Kuznets curve has a number of weaknesses that need to be addressed.

\section{The Data}

The data is an annual time series aimed to be used in time series regression analysis of three countries, namely China, Korea and Japan. The data spanned from 1971 to 2006 and contained the key variables CO2, GDP, and Openness and some information on the source of $\mathrm{CO} 2$ emissions and the variables underlying openness.

$\mathrm{CO} 2$ emissions, measured in metric tons, were transformed into a per capita measure to adjust for the population size of the three countries. GDP was measured as real GDP per capita. A country-specific GDP deflator was used to convert the monetary values into fixed ones. Openness, a measure of trade liberalization, was measured as the sum of imports and exports as a share of total GDP in a given year.

The carbon dioxide emission variables are obtained from Carbon Dioxide Information Analysis Center (CDIAC). The source of Real GDP per capita and openness is the Penn World Table 6.3. A number of variables (RE, FOP and energy type shares) are added to account for the nature of the energy system. RE is the contribution of renewable energies and energy from waste. This data is sourced from OECD data. The FOP data were drawn from the 2009 BP Statistical Review of World Energy. Through this source, we obtained data on the consumption of oil (in million tons), natural gas (in million tons of oil equivalent), and coal (in million tons of oil equivalent). These three variables were totaled for each country and then divided by the total population of the country to obtain FOP (fossil consumption per capita).

Table1: Definition and descriptive statistics of the variables, 1971-2006.

\begin{tabular}{|l|l|r|r|r|r|r|r|}
\hline & & \multicolumn{2}{|c|}{ China } & \multicolumn{2}{c|}{ Korea } & \multicolumn{2}{c|}{ Japan } \\
\hline Variables & Definition & \multicolumn{1}{|c|}{ Mean } & \multicolumn{1}{|c|}{ Std. Dev } & Mean & Std. Dev & Mean & Std. Dev \\
\hline $\begin{array}{l}\text { CO2- } \\
\text { emission }\end{array}$ & CO2 emissions in Mt & 2306.249 & 1192.676 & 11447.640 & 148.825 & 1013.063 & 151.843 \\
\hline CO2 & $\begin{array}{l}\text { CO2 / Population (ton } \\
\text { CO2/capita) }\end{array}$ & 2.013 & 0.801 & 5.548 & 2.915 & 8.359 & 0.890 \\
\hline RE & $\begin{array}{l}\text { Contribution of } \\
\text { renewable energies (\%) }\end{array}$ & 26.586 & 6.942 & 0.731 & 0.269 & 3.031 & 0.544 \\
\hline FOP & $\begin{array}{l}\text { Fossil consumption/ } \\
\text { capita x 100 }\end{array}$ & 0.059 & 0.023 & 0.200 & 0.124 & 0.254 & 0.027 \\
\hline GDP & Real GDP per capita & 2379.074 & 1837.098 & 244.934 & 6415.589 & 23317.610 & 5174.324 \\
\hline OPEN & The degree of openness & 32.800 & 13.768 & 39.922 & 19.649 & 17.448 & 4.479 \\
\hline
\end{tabular}


A summary of statistics in the annual time series data is presented in Table 1. Japan's emission per capita is the highest, followed by Korea and China. A similar pattern is found concerning GDP per capita. China has a much higher share of renewable energy sources in its per capita energy consumption, while Japan has a higher share of fossil consumption per capita. Korea, followed by China, has a relatively higher dependency on an imported primary source of energy than Japan.

Figure 2 shows the development of $\mathrm{CO} 2$ over time in level and changes for the three countries. Figure 2.A on the left shows the development of the $\mathrm{CO} 2$ level over time, while Figure 2.B on the right shows the trends in the growth rate of total carbon dioxide emissions of individual countries normalized at 1971 values.
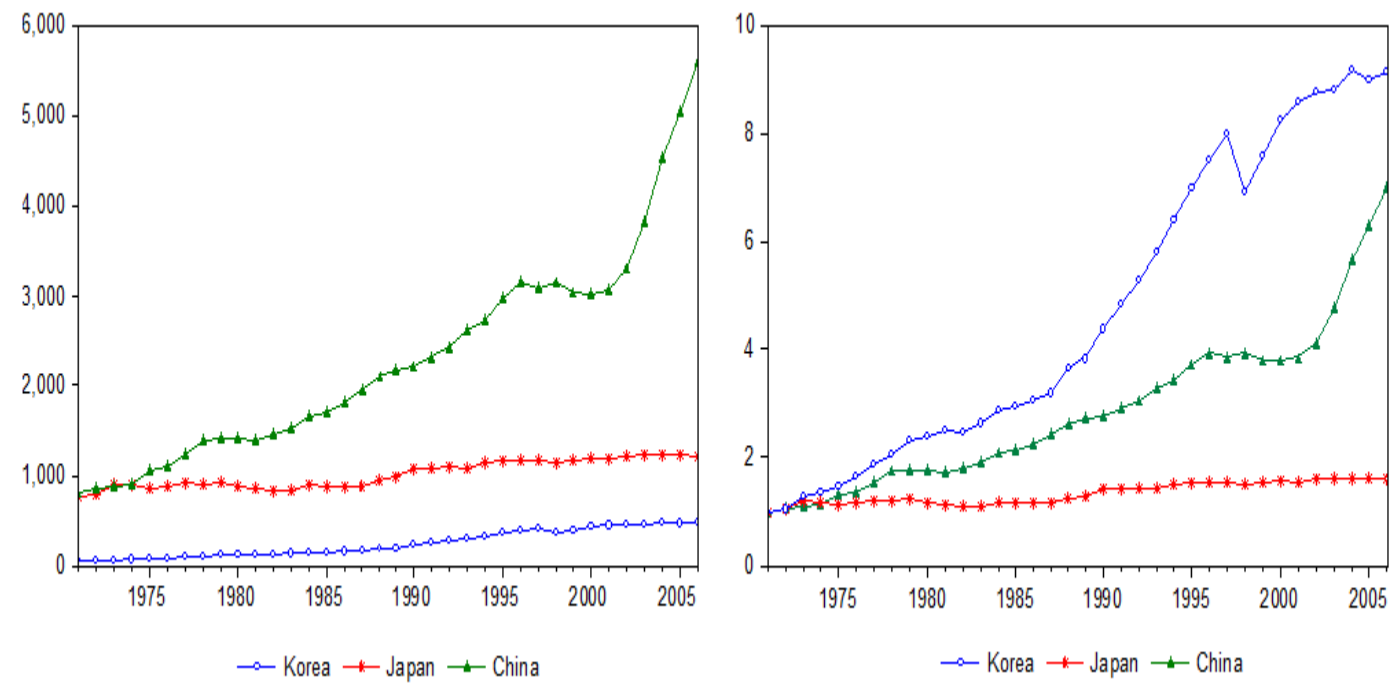

Figure 2.A and 2.B: The trends of carbon dioxide and its growth rate 1971-2006.

Generally, $\mathrm{CO} 2$ emissions tend to increase. In Korea, there is a declining area in relation to the Asian Financial Crisis but $\mathrm{CO} 2$ emissions were on the rise again after 1998 and in relation to the recovery of the economy. At the beginning the level of CO2 was close in Japan and the economic reform in China changed the situation dramatically and by the end of the period in China the gap had increased by more than 6-fold. China also has the fastest increasing trend but we can find a slowdown and even slight decline after the Tiananmen square riots. The graph shows a rapid rise in the $\mathrm{CO} 2$ emissions since 2001. CO2 emissions fluctuated a lot in the case of Japan; however, its trend is slowly increasing, in particular after 1985. The Figure 2.B displays emission trends of three sample countries jointly in the same graph normalized at 1971 values. The objective is to enable a comparison of the level and its development concerning the relative emission of each country. Here the Figure 2.B shows that the growth rate is much higher in Korea than in China, but the gap has been shrinking since 2002. The growth in Japan is very low and the level is relatively constant during the entire period. 


\section{Empirical Analysis}

\subsection{Specification of Environmental Kuznets curve}

We specify and estimate the environmental Kuznets curve (EKC) based on $\mathrm{CO} 2$ emissions per capita for China, Korea and Japan to determine whether these countries have an EKC. The results are expected to have important implications for the countries as they establish environmental targets for $\mathrm{CO} 2$ emissions. To verify the shape of the EKC, we specify and estimate the following multiple regression equations for each country:

$$
\begin{aligned}
\ln C O 2_{t} & =\alpha_{0}+\alpha_{1} \ln G D P_{1}+\alpha_{2}\left(\ln G D P_{t}\right)^{2}+\alpha_{4} \text { OPEN }_{t}+\alpha_{5} \text { OPEN }_{t}^{2} \\
& +\alpha_{6} \ln R E_{t}+\alpha_{7} \text { Trend }_{t}+\alpha_{8} \ln F O P_{t}+\varepsilon_{t} \\
\ln C O 2_{t} & =\alpha_{0}+\alpha_{1} \ln G D P_{1}+\alpha_{2}\left(\ln G D P_{t}\right)^{2}+\alpha_{3}\left(\ln G D P_{t}\right)^{3}+\alpha_{4} \text { OPEN }_{t} \\
& +\alpha_{5} \text { OPEN }_{t}^{2}+\alpha_{6} \ln R E_{t}+\alpha_{7} \text { Trend }_{t}+\alpha_{8} \ln F O P_{t}+\varepsilon_{t}
\end{aligned}
$$

where $\mathrm{CO} 2$ denotes $\mathrm{CO} 2$ emissions per capita and is an endogenous variable that represents better environmental quality if it is a lower level. The main exogenous variables are lnGDP which is logarithm of GDP per capita and OPEN representing trade openness or trade dependence on foreign countries. To test the presence of EKC, the equation (1) and (2) which are derived from the relationships between pollution levels and GDP and Openness will be used. The relationships are estimated as being conditional on renewable energy share, fossil energy consumption and time trend.

Pollution levels are expected to increase with growing income up to a threshold level beyond which pollution levels are expected to decrease with higher income levels. The combination of these two effects, $\alpha_{1}>0$ and $\alpha_{2}<0$ in Model (1), creates the inverted U-shaped relationship between per capita $\mathrm{CO} 2$ emissions and GDP. A representative inverted U-shape example of an expected EKC is shown in Figure 3.A Furthermore, we can easily test the presence of an N-shaped curve (Figure 2.B) by using cubic functional form $\left(\alpha_{3}>0\right)$ as shown in Model (2). In the EKC empirical analysis based on the $\mathrm{SO} 2$ pollution case, $\mathrm{N}$-shaped curve is found by Torras and Boyce (1998), List and Gallet (1999), Bradford et al. (2005), and others. Therefore, this paper adds a variable $\mathrm{GDP}^{3}$ representing a cubic model specification to verify the existence of $\mathrm{N}$-shaped relationships between carbon dioxide and economic growth.

In an attempt to broaden the concept of EKC, we investigate the relationship between environmental quality and trade openness. This is motivated by the fact that at early stages of economic development, free trade leads to an increase in real income, and at the same time, it increase the pollution level because environmental quality is regarded as a luxury good and not a normal good. However, as the country achieves a certain level of GDP, the increased income from free trade encourages consumers to increase their demand for a clean environment and then an attempt is made to reduce environmental damage through increasing clean production and eventually to improve environmental quality (Galeotti and Lanza, 1999). Based on the pattern described above, a country tends to follow increasing pollution levels as trade openness proceeds $\left(\alpha_{4}>0\right)$, and then we can find declining pollution levels at more advanced stage of free trade $\left(\alpha_{5}<0\right)$. We have already explained the variable of RE and FOP, so in this part, we will skip explanations of these conditional variables. Trend is a time trend 
variable used as a proxy to represent the effects of other exogenous time dependent variables such as the trend in pollution abatement, environmental policy change and technological change.

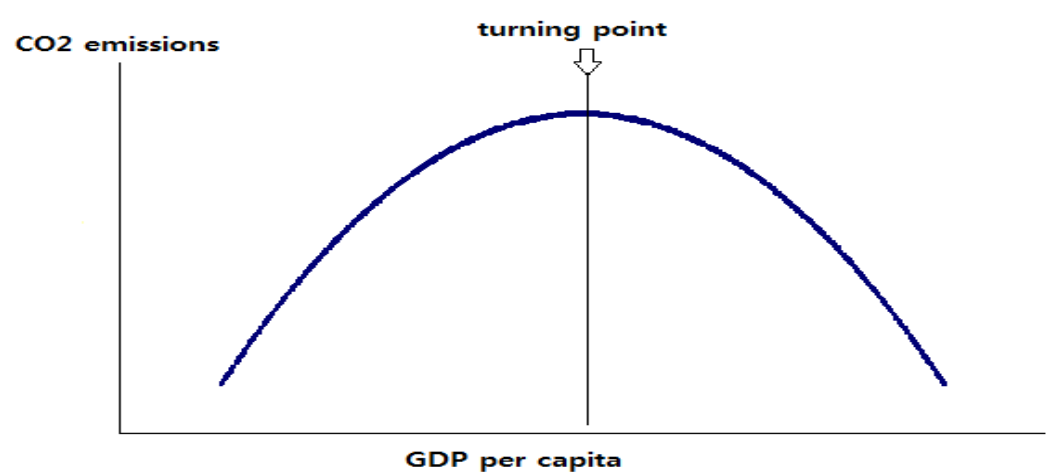

Figure 3.A: The inverted U-shaped Environmental Kuznets Curve

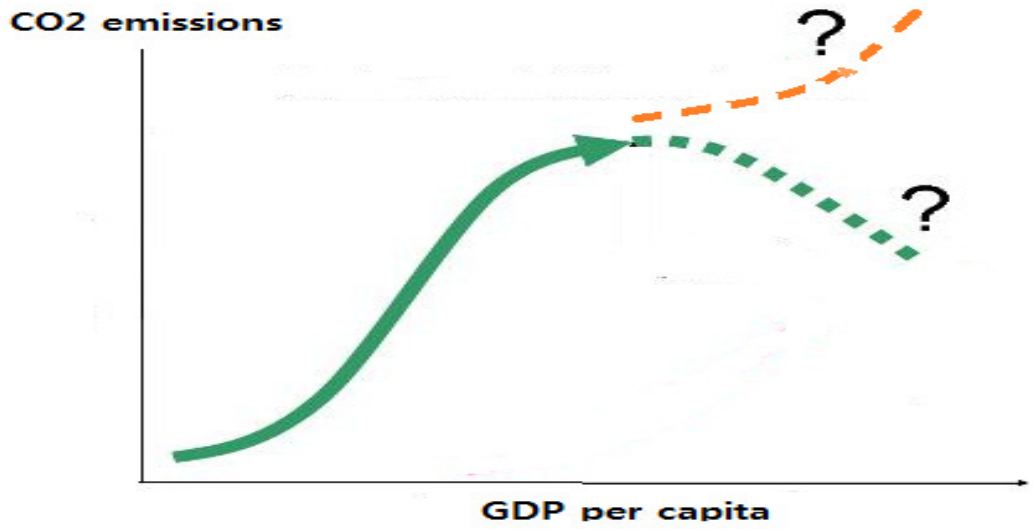

Figure 3.B: The N-shaped Environmental Kuznets curve

\subsection{Empirical Results}

As noted above, estimating and quantifying the effect of free trade on income and environmental quality is necessarily an empirical problem and it varies according to circumstances such as individual countries' development stage, the degree of openness, population and policies of the countries. In this paper we deal with the exogenous variables such as GDP, OPEN and other indicators of environment and development. Through individual countries' OLS estimation result, we can obtain an estimation of the effects on each country's environment. Separate country regressions allow for heterogeneous effects in response to differences in level of development of the sample countries. Thus, in order to investigate the relationships between environmental degradation, economic growth and trade liberalization, here we use simple OLS regression analysis. Table 2 reports the estimation results. 
Table 2 summarizes the regression results for each country based on the two model specifications, differing with square and cubic GDP specifications. Since the two models differ only by one parameter, the t-test can be used to determine the level of generality of the model. A matter of primary concern is the estimated coefficients, their signs and significance. We are interested in not only quadratic Model 1, but also cubic Model 2 to establish the absence of EKC, inverted-U or N-shaped nature of the Kuznets curve.

Table 2: Results from OLS estimation method $(\mathrm{T}=37)$.

\begin{tabular}{|c|c|c|c|c|c|c|}
\hline & \multicolumn{2}{|c|}{ China } & \multicolumn{2}{|c|}{ Korea } & \multicolumn{2}{|c|}{ Japan } \\
\hline & Model 1 & Model 2 & Model 1 & Model 2 & Model 1 & Model2 \\
\hline Constant & $\begin{array}{c}11.28983 * * * \\
(4.9389) \\
\end{array}$ & $\begin{array}{c}7.69721 * * * \\
(3.4422)\end{array}$ & $\begin{array}{c}27.62023^{* * * *} \\
(6.0186) \\
\end{array}$ & $\begin{array}{c}26.51399 * * * \\
(7.6471) \\
\end{array}$ & $\begin{array}{c}49.43529 * * * \\
(12.020)\end{array}$ & $\begin{array}{c}54.67682 * * * \\
(11.5849) \\
\end{array}$ \\
\hline GDP & $\begin{array}{l}2.41 \mathrm{E}-05 \\
(0.2366)\end{array}$ & $\begin{array}{c}0.00086^{* * * *} \\
(3.2158)\end{array}$ & $\begin{array}{c}-0.00031 * * * \\
(-3.4569)\end{array}$ & $\begin{array}{c}-0.00049 * * * \\
(-6.3095)\end{array}$ & $\begin{array}{c}-0.00035 * * * \\
(-2.8226)\end{array}$ & $\begin{array}{c}-0.00159 * * \\
(-2.4923)\end{array}$ \\
\hline $\mathrm{GDP}^{2}$ & $\begin{array}{c}1.97 \mathrm{E}-08^{*} \\
(1.9269)\end{array}$ & $\begin{array}{c}-1.52 \mathrm{E}-07 * * * \\
(-2.8866)\end{array}$ & $\begin{array}{c}1.90 \mathrm{E}-08 * * * \\
(7.2172)\end{array}$ & $\begin{array}{c}3.13 \mathrm{E}-08 * * * \\
(9.4679)\end{array}$ & $\begin{array}{c}\text { 7.99E-09*** } \\
(2.9193)\end{array}$ & $\begin{array}{c}6.77 \mathrm{E}-08^{* * *} \\
(2.2365)\end{array}$ \\
\hline $\mathrm{GDP}^{3}$ & $\begin{array}{l}- \\
- \\
\end{array}$ & $\begin{array}{c}1.12 \mathrm{E}-11 * * * \\
(3.3067)\end{array}$ & $\begin{array}{l}- \\
- \\
\end{array}$ & $\begin{array}{c}-2.81 \mathrm{E}-26 \text { *** } \\
(-4.6396)\end{array}$ & - & $\begin{array}{c}-9.17 \mathrm{E}-13^{*} \\
(-1.9795)\end{array}$ \\
\hline OPEN & $\begin{array}{l}-0.02270^{*} \\
(-2.4854)\end{array}$ & $\begin{array}{c}-0.02768^{* * * *} \\
(-3.4801)\end{array}$ & $\begin{array}{c}0.07756^{* * * *} \\
(3.7144)\end{array}$ & $\begin{array}{l}-0.01384 \\
(-0.5490)\end{array}$ & $\begin{array}{l}0.08298 \\
(0.9852)\end{array}$ & $\begin{array}{l}0.09749 \\
(1.2134)\end{array}$ \\
\hline $\mathrm{OPEN}^{2}$ & $\begin{array}{c}0.00024^{*} \\
(1.9206)\end{array}$ & $\begin{array}{c}0.00041 * * * \\
(3.4182)\end{array}$ & $\begin{array}{c}-0.00089 * * * \\
(-5.1414)\end{array}$ & $\begin{array}{l}4.16 \mathrm{E}-05 \\
(0.1723)\end{array}$ & $\begin{array}{l}-0.00218 \\
(-1.2146) \\
\end{array}$ & $\begin{array}{l}-0.00155 \\
(-0.8906)\end{array}$ \\
\hline $\mathrm{RE}$ & $\begin{array}{c}-0.06152 * * * \\
(-3.5965)\end{array}$ & $\begin{array}{c}-0.07239 * * * \\
(-4.8291)\end{array}$ & $\begin{array}{l}0.04843 \\
(0.3283)\end{array}$ & $\begin{array}{l}-0.08182 \\
(-0.7136)\end{array}$ & $\begin{array}{l}0.12545 \\
(1.2545)\end{array}$ & $\begin{array}{l}0.05252 \\
(0.5154)\end{array}$ \\
\hline Trend & $\begin{array}{l}-0.01922 \\
(-1.4797) \\
\end{array}$ & $\begin{array}{c}-0.04951 * * * \\
(-3.4392)\end{array}$ & $\begin{array}{c}-0.43874 * * * \\
(-3.7855)\end{array}$ & $\begin{array}{l}0.07547 \\
(0.5347)\end{array}$ & $\begin{array}{l}0.00689 \\
(0.3776) \\
\end{array}$ & $\begin{array}{l}-0.00645 \\
(-0.3465) \\
\end{array}$ \\
\hline FOP & $\begin{array}{c}0.94606 * * \\
(2.6709) \\
\end{array}$ & $\begin{array}{l}0.48827 \\
(1.4663)\end{array}$ & $\begin{array}{l}3.41883^{* * * *} \\
(6.2256)\end{array}$ & $\begin{array}{l}3.05923 * * * \\
(7.2647)\end{array}$ & $\begin{array}{c}6.46996^{* * * *} \\
(8.8037)\end{array}$ & $\begin{array}{c}5.95312 * * * \\
(7.9868)\end{array}$ \\
\hline $\mathrm{R}^{2}$ & 0.9951 & 0.9965 & 0.9985 & 0.9992 & 0.9891 & 0.9905 \\
\hline F-value & 784.2839 & 940.1131 & 2613.3790 & 4027.8280 & 350.6743 & 340.4996 \\
\hline DW-statistics & 1.8549 & 2.3707 & 1.8587 & 2.2016 & 1.6817 & 1.7348 \\
\hline
\end{tabular}

Note: significant at the $1 \%(* * *), 5 \%(* *)$ and $10 \%(*)$ levels of significance. t-values in parenthesis.

In the case of Korea, GDP per capita and its square are statistically significant in Model 1 , and the cubic component in Model 2 was also statistically significant. On the other hand unlike in Model 1 the OPEN and its square term in Model 2 are statistically insignificant. The Durbin-Watson statistics for these models are respectively, 1.8587 in Model 1 and 2.2016 in Model 2. The Durbin-Watson statistic is a test for first-order serial correlation. The DW test statistic 2.2016 in Model 2 rejects the null hypothesis that there is no positive serial correlation, but the test result for Model 1 cannot reject the null hypothesis. Therefore, these statistics suggest that the estimated standard errors and the significance of the coefficients of the parameters in Model 1 are reliable. Therefore, Model 1 is more suitable for estimating the EKC for Korea.

In looking at the estimated coefficient of GDP, we notice that it is negative and that the $\mathrm{GDP}^{2}$ has a positive sign. This shows that economic growth does not have the expected Kuznets effect on environmental circumstances in Korea. At the early stage of economic growth, environmental pollution cannot be avoided, but when reaching a 
higher level, however, circumstances would gradually be improved as the level of development and welfare improves. The result is in contradiction to the expected one and thereby cannot find an inverted U-shaped threshold point. In Figure 3 we show the results of regressions of per capita $\mathrm{CO} 2$ emissions on per capita GDP. Here we can find evidence of a U-shaped EKC. The turning point ${ }^{3}$ is estimated to be $\$ 8210$. In the early stage, there is declining trend but it immediately begins to rise after the turning point. This result refutes the EKC hypothesis in the case of Korea.

Dependence on foreign trade has a significant impact on $\mathrm{CO} 2$ emissions. The variables OPEN and OPEN ${ }^{2}$ exhibit inverted U-shaped relationships with $\mathrm{CO} 2$ emissions. Similar conclusions are reached by Taskin and Zaim (2000), there is almost a common agreement that there exists a U-curve type quadratic relationship with the environmental quality where OPEN represents a positive coefficient and OPEN ${ }^{2}$ shows negative coefficient. At the early stage of free trade, it leads to increased environmental pollution but when individual countries exceed certain level of openness then the conditions for a polluted environment would be improved. This is because the more trade circumstances liberalize, the more people make an effort to meet international environmental standards for international trade, collaboration and competition purposes. RE shows a positive relationship but this variable is not statistically significant. Time trend represents the technological change and it represents a negative $\mathrm{CO} 2$ relationship with time suggesting a decline in emissions as was our expectation. As technologies develop, it is conducive to environmental quality.

In the case of China, GDP per capita and $\mathrm{CO} 2$ emissions are shown not to be statistically significantly related to Model 1 but they are to Model 2. For this reason we find Model 2 to be more suitable to estimate the EKC in China's case. We notice the positive coefficient of GDP, negative coefficient of $\mathrm{GDP}^{2}$ and again the positive coefficient of $\mathrm{GDP}^{3}$. These together suggest an $\mathrm{N}$-shaped curve describing the relationship between pollution and GDP. The initial deterioration of environmental conditions and then economic growth causing an improvement of the environment, in spite of the efforts of environment-friendly development, environmental circumstances cannot get better continually. Through the signs of the coefficient, we think intuitively, the curve has an $\mathrm{N}$-shape. However, after depicting the graph, we can work out that the cubic function is monotonically an increasing function which does not have any external value. In cases with such pattern there is no use verifying the threshold point on the EKC.

\footnotetext{
3 The conditions for this to occur are for estimated coefficient $\alpha_{1}>0, \alpha_{2}<0$, its turning point is computed as $-\alpha_{1} / 2 \alpha_{2}$.
} 

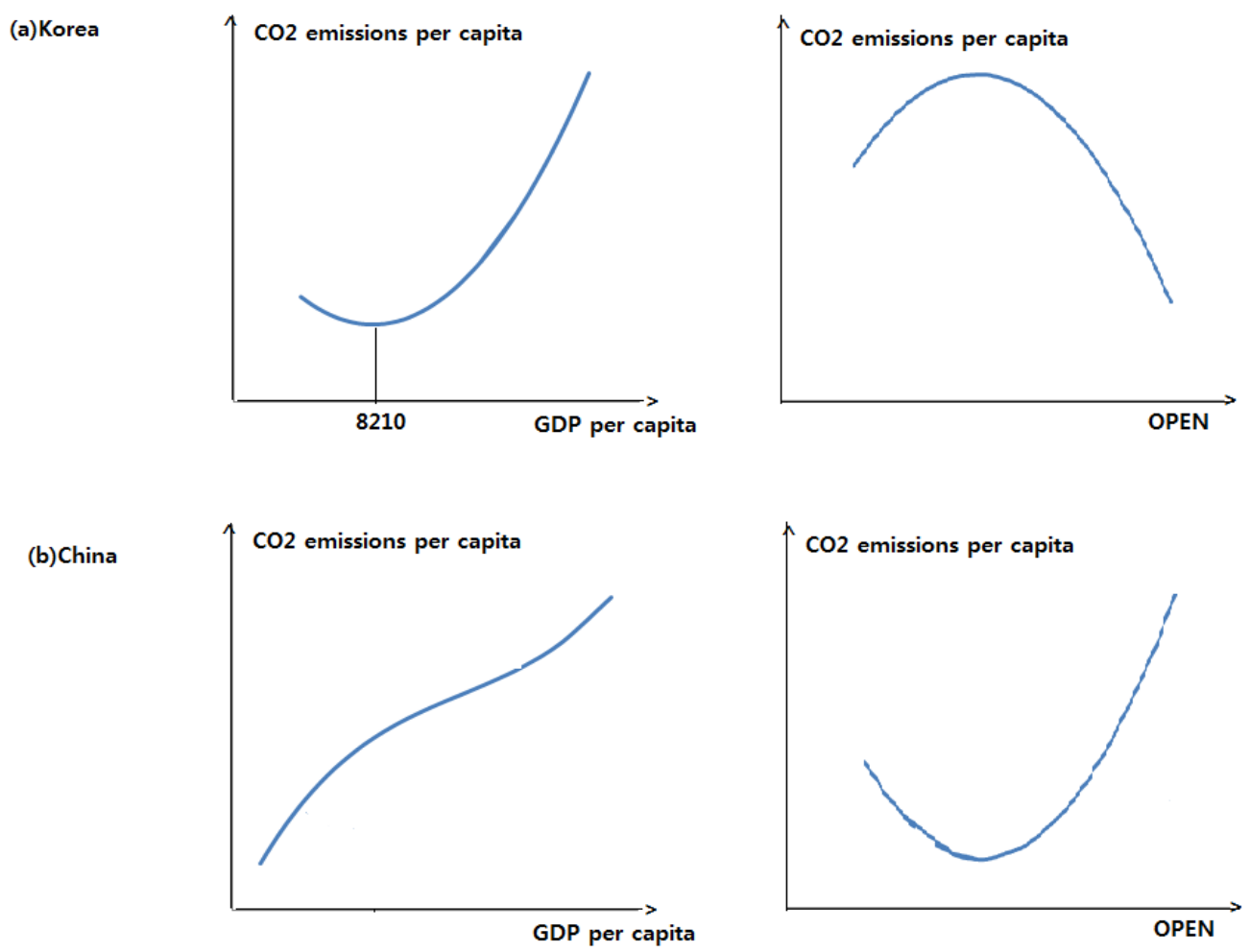

(c)Japan
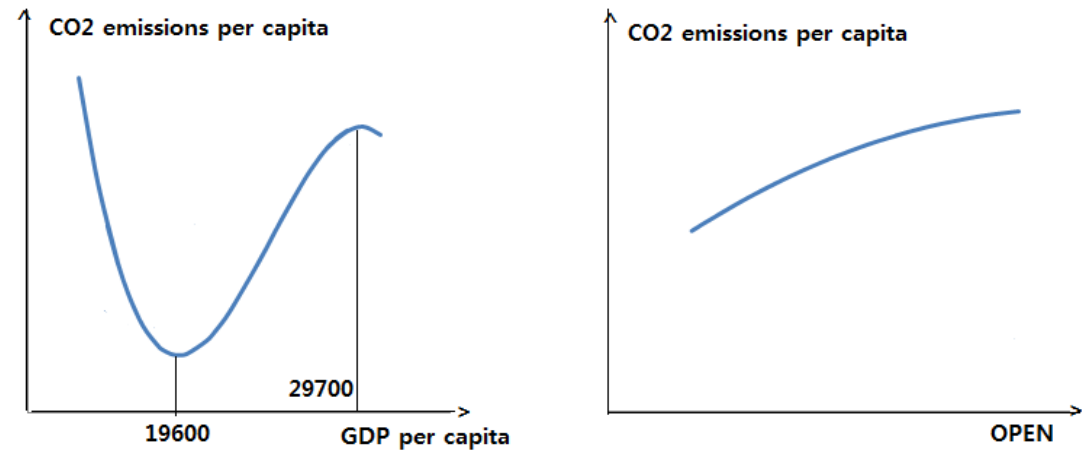

Figure 4: The EKC for $\mathrm{CO} 2$ emission per capita in China, Korea and Japan

Also in China's case, the variables related to free trade have a significant impact on the environment. These openness variables represent a U-curve type quadratic relationship with the $\mathrm{CO} 2$ emissions. It means that there is a threshold level of openness, but in reversed form. RE and Trend represent negative and by expectation consistent relationships. Increasing the amount of application of New and Renewable Energy sources and developing the technology of energy efficiency can contribute to a decrease in emissions in China.

In the case of Japan, it was difficult to determine the more appropriate model. The DW test statistic was not helpful in selecting the appropriate model. In Model 1, beyond a certain level, $\mathrm{CO} 2$ emissions showed an increasing trend. The estimated turning point 
was $\$ 29,700$ in terms of GDP per capita. In spite of many efforts to reduce carbon dioxide emissions, it is not easy to achieve desired reductions if economic growth is based upon a premise. In Model 2, their respective signs suggest an inversed $\mathrm{N}$-shaped curve. The relative minimum turning point is calculated at $\$ 19,600$ and the relative maximum turning point is calculated to be $\$ 29,700$. Although both models are significant, this paper prefers Model 2 because it contains additional information. Through this regression, we notice that Japan has an inversed $\mathrm{N}$-shaped curve which exhibits the inverted U-shaped curve in the later parts of the curve.

In terms of openness, the more economy is dependent on trade, the more carbon dioxide is emitted. However, if Japan exceeds a certain level of openness, then CO2 emissions decrease. This is interpreted that the rise in GDP through trade will in turn generate increases in demand for environmental goods. Part of the gain is then used to alleviate environmental pollution. However, it is not statistically significant and thereby hard to determine that there exists a decreasing part.

\section{The Vector Autoregressive and Vector Error Correction Models}

\subsection{The framework}

After having established the relationship between CO2 emissions, GDP and openness, this paper uses a vector auto regression (VAR) to test the short-run relationship among the determinants of environmental variables. VAR has the advantage that it is very useful by allowing all variables to interact with themselves (past values) and with each others in regression analysis without any theoretical structure on the estimators. Furthermore, VAR which can conduct dynamic analysis is useful to overcome the static disadvantage of OLS because VAR can explain the dynamic structure of time series better than the static OLS estimation method but at the expense of complexity in interpretation of effects. In time series data, most of the indicators tend to have trends. To avoid this problem, non-stationary variables should be differentiated at least once to transform them into a stationary form.

Through such a transformation process, we can make the variables stationary, but the differentiation procedure may entail some loss of the long-term characteristics of the original data. However, Engle and Granger (1987) proposed that even though all the variables in the model are non-stationary, the series may be stationary if the variables have a linear combination. In such a case, we can consider the variables to be cointegrated. Because the use of VAR depends on the stationary condition of the data set, we first briefly discuss and present the results of a unit root test-the augmented Dickey-Fuller (ADF) test.

Another test to be conducted is the adaption of the Johansen's Cointegration test which will follow. If there exists a long-run equilibrium relationship, we will adopt the Vector Error Correction Model (VECM). Through the Error Correction Mechanism, a proportion of the disequilibrium in one period is corrected in the next period. Engle and Granger (1987) proposed that once the variables are determined to be cointegrated, there always exists a corresponding error correction representation, implying that changes in the dependent variable are a function of the level of disequilibrium in the cointegrating relationship captured by the error correction term (ECT). The ECT is 
used to correct such disequilibrium, and thus, we used it to examine the short-run and long-run relationships between $\mathrm{CO} 2$ emissions and its determinants.

\subsection{Unit roots and Cointegration tests results}

The possibility of the nonstationarity of time series data raises an important issue. A stationary series is defined as a series that tends to return to its mean value and fluctuate around it within a more or less constant range, whereas a non-stationary series is defined as a series whose means differ at different points in time and variance increases with the sample size (Harris \& Sollis, 2003). If a data set contains non-stationary series, OLS cannot provide valid estimation results and interpret various relationships. Most parts of economic variables generally are non-stationary. To avoid this problem, nonstationary variables should be differentiated. The variables are differentiated $\mathrm{d}$ times and then stationary and OLS results are valid in interpretation.

The Unit root test is conducted to test stationary. Individual variables are tested by the Augmented Dickey-Fuller (ADF) test and the results are shown in Table 3.

Table 3: Results of Unit Roots Tests

\begin{tabular}{|l|c|c|c|}
\hline Test statistics & $\log (\mathrm{CO} 2)$ & $\log (\mathrm{GDP})$ & $\log (\mathrm{OPEN})$ \\
\hline \multicolumn{5}{|c|}{ China } \\
\hline Level t-value & 0.1252 & -3.5435 & -1.1566 \\
\hline The first differences & $-3.4044 * * *$ & $-4.7947 * * *$ \\
\hline \multicolumn{5}{|c|}{ Korea } \\
\hline Level t-value & $-1.9837 \quad-5.6869 * * *$ & $-5.6787 * * *$ & 0.9824 \\
\hline The first differences & $-1.3957 \quad 0.1769 * * *$ \\
\hline \multicolumn{5}{|c|}{ Japan } & 0.4453 & 0.4453 \\
\hline Level t-value & $-5.1872 * * *$ & $-6.6458 * * *$ & $-6.6458 * * *$ \\
\hline The first differences &
\end{tabular}

From Table 3 we note that, in the case of Korea, the result of unit root tests show that the t-statistic of $\mathrm{CO} 2$ is -1.9837 . Therefore, a null hypothesis of non-stationarity cannot be rejected. The ADF-test statistic is the t-statistic for the variables of interest. If the absolute value of the ADF-test statistic is smaller than a certain value like $1 \%$ or $5 \%$ level of significance, we cannot reject the null hypothesis. The results indicate that each of the series is non-stationary at the $1 \%$ level. After the first differentiated $\mathrm{CO} 2$ emission, the null hypothesis of non-stationary is clearly rejected at the $1 \%$ significance level. As a result, the first-differencing the $\mathrm{CO} 2$ emission removes the non-stationary and any other variables are equal. In the cases of China and Japan also the nonstationary is removed when applying the first differenced transformation of the variables.

In any time series analysis, it is important to determine whether one economic variable can help forecast another. For example, If x Granger-causes y but y does not Granger cause $\mathrm{x}$, then the past value of $\mathrm{x}$ is useful in predicting the current and future values of y. The Granger causality test assumes that the information is related to each variable. 
To confirm how the variables are arranged in the vector form, this step applied the pairwise Granger causality tests. We conducted the test to determine the direction of causality and the short-run effect of the relationship. This process requires the use of the VAR or VEC model because the results obtained using the model are influenced by the ordering of variables. The result of the Granger causality tests show that in the case of China, Korea and Japan, OPEN Granger-causes GDP. According to the results of the causality tests, we determined an ordering of the variables in the following way:

$$
C O 2_{t}=f\left(C O 2_{t-p}, \text { OPEN }_{t}, \text { OPEN }_{t-p}\right)
$$

where $\mathrm{p}$ is the number of lags in the model. Prior to finding the proper number of lag, we decided to use a VAR model. In general, SC (Schwartz Information Criterion), AIC (Akaike Information Criterion) and HQC (Hannan-Quinn Information Criterion) are used to determine the optimal number of lags (p). In this paper, AIC is selected to estimate the optimal lag because SC tends to underestimate the lag (p). Under the lag length selection rule we have chosen the smallest value and this paper uses 5 lags as the maximum lag length. The optimal lag order length is selected by the criterion, in Korea $\mathrm{p}=5$, in China $\mathrm{p}=3$ and in Japan $\mathrm{p}=2$ (see Table 4).

Table 4: Results of Information Criterion

\begin{tabular}{|c|r|r|r|r|r|r|r|r|r|}
\hline & \multicolumn{4}{|c|}{ China } & \multicolumn{3}{c|}{ Korea } & \multicolumn{3}{c|}{ Japan } \\
\hline Lag & AIC & SC & HQC & AIC & SC & HQC & AIC & SC & HQC \\
\hline 0 & -0.807 & -0.669 & -0.762 & 35.633 & 35.772 & 35.678 & -4.9762 & -4.837 & -4.931 \\
\hline 1 & -9.004 & $-8.449^{*}$ & -8.823 & 27.871 & $28.426^{*}$ & 28.052 & -13.081 & $-12.525^{*}$ & -12.900 \\
\hline 2 & -9.406 & -8.435 & -9.090 & 28.027 & 28.998 & 28.344 & $-13.433^{*}$ & -12.461 & $-13.116^{*}$ \\
\hline 3 & $-9.669^{*}$ & -8.281 & $-9.217^{*}$ & 28.149 & 29.537 & 28.602 & -13.184 & -11.797 & -12.732 \\
\hline 4 & -9.542 & -7.738 & -8.954 & 27.733 & 29.537 & 28.321 & -13.072 & -11.268 & -12.484 \\
\hline 5 & -9.529 & -7.309 & -8.806 & $26.820^{*}$ & 29.040 & $27.544^{*}$ & -13.105 & -10.884 & -12.381 \\
\hline
\end{tabular}

Note: * indicate lag order selected by the criterion

In the analysis of the VAR model, each variable should be stationary, and there must be no cointegration among the variables. To determine whether the variables were cointegrated, we used the Johansen cointegration test. Through this test, we can choose among the two VAR or VECM models. If the data is stationary and the variables are cointegrated, a VECM model is preferred. To test for the co-integration relationship, this paper uses lag length chosen by the information criteria above. The result of the Johansen co-integration test is reported in Table 5.

In the case of Korea, the null-hypothesis of zero and $r \leq 1$ is rejected at the $5 \%$ level of significance. On the other hand, the null-hypothesis of $r \leq 2$ cannot be rejected at any level of significance. Based on this result, it is determined that these variables have two cointegrating vectors representing a long-run relationship. As a result, it is determined that these variables would be analyzed by the VECM model. The result from the Johansen and Julius (1990) methods indicate the presence of cointegrated vectors. It suggests that, there are long-run relationships among variables. As a result, the data is non-stationary and variables are cointegrated and so the VECM model is 
adopted here to the analysis of the series. In the case of China, the null-hypothesis of zero is rejected at the $5 \%$ level so there is one cointegrating vector. In this case we also use the VECM model. For the Japan case, all of the null-hypothesis is not rejected at the $5 \%$ level. Hence, we can conclude that there is no cointegrating vector and the VAR model will be adopted for the Japanese data.

Table 5: Results of Johansen Cointegration Test

\begin{tabular}{|c|c|c|c|c|c|}
\hline $\begin{array}{l}\text { Hypothesized } \\
\text { No. of CE(s) }\end{array}$ & \multicolumn{2}{|c|}{ Eigen value } & $\begin{array}{c}\text { Trace } \\
\text { Statistic }\end{array}$ & \multicolumn{2}{|c|}{$\Lambda-\max$} \\
\hline \multicolumn{6}{|c|}{ China } \\
\hline None $*$ & $r=0$ & $\mathrm{r}=1$ & 0.66738 & 44.7673 & 36.3254 \\
\hline At most 1 & $r \leq 1$ & $r=2$ & 0.16182 & 8.44195 & 5.82530 \\
\hline At most 2 & $r \leq 2$ & $r=3$ & 0.07623 & 2.61665 & 2.61665 \\
\hline \multicolumn{6}{|c|}{ Korea } \\
\hline None $*$ & $r=0$ & $\mathrm{r}=1$ & 0.58513 & 43.0919 & 27.2741 \\
\hline At most $1 *$ & $r \leq 1$ & $r=2$ & 0.39934 & 15.8177 & 15.8018 \\
\hline At most 2 & $r \leq 2$ & $r=3$ & 0.00051 & 0.01592 & 0.01592 \\
\hline \multicolumn{6}{|c|}{ Japan } \\
\hline None * & $r=0$ & $\mathrm{r}=1$ & 0.22830 & 13.4583 & 8.81147 \\
\hline At most $1 *$ & $r \leq 1$ & $r=2$ & 0.12372 & 4.64683 & 4.49069 \\
\hline At most 2 & $r \leq 2$ & $r=3$ & 0.00458 & 0.15613 & 0.15613 \\
\hline
\end{tabular}

Note: * Significant at the $5 \%$ level

\subsection{The VAR Model}

The Vector Autoregression (VAR) model suggested by Johansen is used to investigate the dynamic interrelationships between $\mathrm{CO} 2$ emission, GDP and Openness. The Johansen method uses this model including up to $\mathrm{k}$ lags as follow:

$$
X_{t}=u+A_{0}+A_{1} X_{t-1}+A_{2} X_{t-2}+\ldots+A_{k} X_{t-k}+u_{t}
$$

where

$$
X_{t}=\left[\begin{array}{l}
\text { Open }_{t} \\
G D P_{t} \\
C O 2_{t}
\end{array}\right] \text { and } u_{t}=\left[\begin{array}{l}
u_{1 t} \\
u_{2 t} \\
u_{3 t}
\end{array}\right]
$$

If all variables are non-stationary, cointegrating vectors exist. Under such conditions, the Vector Error Correction Model (VECM) is defined as:

$$
\Delta X_{t}=u+\Gamma_{1} \Delta X_{t-1}+\Gamma_{2} \Delta X_{t-2}+\ldots+\Gamma_{k-1} \Delta X_{t-k+1} \Pi X_{t-k}+u_{t}
$$

where $X_{t}$ and $u_{t}$ are defined previously. $\Delta$ is the difference operator. $\Gamma_{1}, \cdots, \Gamma_{\mathrm{k}-1}$ are the coefficient matrices of short-run dynamics and $\Pi$ are the matrix of long-run coefficients. Long-run impact is calculated from matrix $\Pi=\alpha \beta^{\prime}$ (Johansen, 1988; and Johansen and Juselius, 1992). 


\subsection{The long-run and short-run relationship (VECM) in Korea and China}

The long-run estimation results for the VECM are reported in Table 6. The coefficient of the ECT $(\alpha)$ which indicates the speed-adjustment coefficient on the long-run correction term and the $\beta$ coefficient which means individual variables' coefficient in the error correction term are reported.

The results show that, in the case of Korea, since all of the $\beta$ coefficients of the ECT's t-statistics are greater than the critical value, it is interpreted that GDP is significant in this equation and OPEN is insignificant. GDP and its square have negative signs. Therefore, GDP is found to have a positive long-run relationship. In China's case, the $\beta$ coefficients of the ECT of GDP have a negative sign while OPEN has a positive sign but OPEN is not statistically significant. Therefore, $\mathrm{CO} 2$ and GDP have a positive long-run relationship. The results based on both Korea and China not only take into consideration the impact of the long-term factors on the equilibrium but they also allow examination of the short-run impacts factors.

Table 6: Long-run Coefficient of the VECM

\begin{tabular}{|c|c|c|c|}
\hline & $\mathrm{CO} 2$ & GDP & OPEN \\
\hline \multicolumn{4}{|c|}{ China } \\
\hline$\beta$ coefficients of the ECT & 1.00000 & $-0.62996 *$ & 0.08608 \\
\hline (standard errors) & & $(0.02671)$ & $(0.06927)$ \\
\hline Coefficient on the $\operatorname{ECT}(\alpha)$ & $-0.25538^{*}$ & $0.18578 *$ & -0.15166 \\
\hline (standard errors) & $(0.10598)$ & $(0.07743)$ & $(0.24865)$ \\
\hline \multicolumn{4}{|c|}{ Korea } \\
\hline$\beta$ coefficients of the ECT & 1.00000 & $-0.02536 *$ & 0.12603 \\
\hline (standard errors) & & $(0.0018)$ & $(0.64538)$ \\
\hline Coefficient on the $\operatorname{ECT}(\alpha)$ & $-1.25677 *$ & $-49.55878 *$ & 0.01101 \\
\hline (standard errors) & $(0.28036)$ & $(11.77440)$ & $(0.04438)$ \\
\hline
\end{tabular}

Note: * Significant at the 5\% level, (standard errors are in parentheses). ECT is error correction term.

The coefficient on the ECT $(\alpha)$, adjustment speed in the long-run for CO2 and GDP in case of Korea is -1.25677 and -49.55878 . If the coefficient value is over-valued, then it will be adjusted downward and vice versa. The ECT suggests that when once a shock emerges, convergence to equilibrium is rapid so that the size of coefficient of the ECT $(\alpha)$ can be interpreted as an adjustment speed. The coefficient on the error correction term implies that a deviation from the equilibrium level during the current period will be corrected in the next period. In the same way, we can analyze the coefficient of the ECT $(\alpha)$ for GDP in China. The size of coefficient on the ECT is interpreted as speed of adjustment, where 0.18578 means that about $18.6 \%$ of the imbalance situation is corrected in the first period.

In Korea, the coefficient of OPEN is significant at the 5\% level and its sign is negative. The degree of openness (OPEN) increases by $1 \%$ and then $\mathrm{CO} 2$ emissions decrease by $5.8 \%$. This negative relation varies from -0.0520 to -0.0852 only in the short-run. On the contrary, OPEN does not have a significant long-run relationship. The coefficient of GDP is not significant at the $5 \%$ level. In the previous statement, we have already 
mentioned our observation that $\mathrm{CO} 2$ has a positive long-run relationship but the relationship of $\mathrm{CO} 2$ and GDP is insignificant in a short-run perspective.

The short-run results based on the VECM model for China and Korea are reported in Table 7. In China, there is no significant short-run relationship between OPEN and $\mathrm{CO} 2$ but the relationship of OPEN and GDP is significant. If GDP increases by $1 \%$, it leads to a $0.67 \%$ increase in $\mathrm{CO} 2$ emission just in the short-run. However, we have already obtained the result that $\mathrm{CO} 2$ and GDP have a positive long-run relationship. In case of China the $\mathrm{CO} 2$ emissions and GDP have a positive relationship regardless of whether it is long-run or short-run.

Table 7: Short-run Coefficient of the VECM

\begin{tabular}{|c|c|c|c|}
\hline & $\Delta \mathrm{CO} 2_{\mathrm{t}}$ & $\Delta \mathrm{GDP}_{\mathrm{t}}$ & $\Delta \mathrm{OPEN}_{\mathrm{t}}$ \\
\hline \multicolumn{4}{|c|}{ China } \\
\hline$\Delta \operatorname{co} 2_{t-1}$ & $0.72255^{*}$ & 0.08195 & $0.15548 *$ \\
\hline$\Delta \operatorname{co} 2_{t-2}$ & 0.09690 & -0.21302 & 0.08384 \\
\hline$\Delta \mathrm{GDP}_{\mathrm{t}-1}$ & $0.66768^{*}$ & 0.25377 & $1.43166^{*}$ \\
\hline$\Delta \mathrm{GDP}_{\mathrm{t}-2}$ & $0.66936^{*}$ & 0.16016 & $-1.92163 *$ \\
\hline$\Delta \mathrm{OPEN}_{\mathrm{t}-1}$ & 0.00819 & 0.04755 & 0.12301 \\
\hline$\Delta \mathrm{OPEN}_{\mathrm{t}-2}$ & -0.06540 & -0.01917 & -0.13983 \\
\hline \multicolumn{4}{|c|}{ Korea } \\
\hline$\Delta \operatorname{co} 2_{\mathrm{t}-1}$ & $1.60505^{*}$ & 0.03353 & $61.01750^{*}$ \\
\hline$\Delta \operatorname{co} 2_{\mathrm{t}-2}$ & $2.28986^{*}$ & 0.16965 & 100.54520* \\
\hline$\Delta \operatorname{co} 2_{t-3}$ & $1.13167 *$ & $0.18171 *$ & $45.85240 *$ \\
\hline$\Delta \operatorname{co} 2_{t-4}$ & $1.98281 *$ & 0.04843 & $51.65980 *$ \\
\hline$\Delta \mathrm{GDP}_{\mathrm{t}-1}$ & 0.69992 & 0.00571 & 58.85880 \\
\hline$\Delta \mathrm{GDP}_{\mathrm{t}-2}$ & 1.08607 & -0.17354 & -38.68920 \\
\hline$\Delta \mathrm{GDP}_{\mathrm{t}-3}$ & -1.32363 & -0.17354 & -38.68920 \\
\hline$\Delta \mathrm{GDP}_{\mathrm{t}-4}$ & -0.93165 & -0.31816 & -38.68920 \\
\hline$\Delta \mathrm{OPEN}_{\mathrm{t}-1}$ & $-0.05754 *$ & -0.00064 & $-2.24494 *$ \\
\hline$\Delta \mathrm{OPEN}_{\mathrm{t}-2}$ & $-0.08521 *$ & -0.00473 & $-3.59916^{*}$ \\
\hline$\Delta \mathrm{OPEN}_{\mathrm{t}-3}$ & $-0.05204 *$ & -0.00307 & $-2.09347 *$ \\
\hline$\triangle \mathrm{OPEN}_{\mathrm{t}-4}$ & $-0.07674^{*}$ & -0.31816 & $-138.96500 *$ \\
\hline
\end{tabular}

Note: ${ }^{*}$ Significant at the $5 \%$ level

Table 8: The results of VAR

\begin{tabular}{|c|c|c|c|}
\hline & $\log (\mathrm{CO} 2)$ & $\log (\mathrm{GDP})$ & $\log (\mathrm{OPEN})$ \\
\hline $\log \left(\mathrm{CO}_{\mathrm{t}-1}\right)$ & $0.85899^{*}$ & $-0.16866^{*}$ & 0.21871 \\
\hline $\log \left(\mathrm{GDP}_{\mathrm{t}-1}\right)$ & $0.12751^{*}$ & $1.01912^{*}$ & -0.01818 \\
\hline $\log \left(\mathrm{OPEN}_{\mathrm{t}-1}\right)$ & -0.07109 & 0.04519 & $0.90097^{*}$ \\
\hline Constant & -0.09093 & $0.86724^{*}$ & -1.02319 \\
\hline
\end{tabular}

\subsection{VAR in Japan}

Table 8 shows the result of VAR estimation for Japan. All variables in the VAR model are transformed into natural logs. As a result of the estimation, we find that the increased GDP in the preceding term increases $\mathrm{CO} 2$ emissions. However, the estimated coefficient of the OPEN is not statistically significant in the equation of the CO2. Even though the VAR model is useful in showing the dynamic relationship among the 
variables, the estimated coefficient is not easy to interpret intuitively. Therefore, variance decompositions (VDCs) and the impulse response functions will be carried out to check the stability of the models.

\subsection{Test of stability}

If the estimated VAR and VECM are stable, then all coefficients should be less than 1 and inside the unit circle. If the VAR and VECM are not stable, analyzing certain results is meaningless. If the number of endogenous variables is $\mathrm{k}$ and the maximum lagged period is $\mathrm{p}$, then the number of unit roots that we have is $\mathrm{k}$ times $\mathrm{p}$. If we estimated the model with $r$ cointegrating relations, then $k-r$ roots lie inside the unit circle. In case of China and Japan, when we use CO2, GDP and OPEN as endogenous variables, this model is a poor VAR and VECM model. As a result, further analysis is not needed because the results do not mean anything. To satisfy the stability, modified models are need. The solution is using the endogenous variables $\log (\mathrm{CO} 2), \log (\mathrm{GDP})$ and $\log (\mathrm{OPEN})$. Here the used VAR and VECM model are not misspecified models.

The VAR and VECM models through the impulse response functions allow for analysis of certain variable's influence on dynamic response of endogenous variables. The results of the VAR/VECM stability test showed that: Korea, VEC specification imposes 1 unit root, China's imposes 2 unit roots of which no roots lies outside the unit circle, and finally in the case Japan, VAR satisfies the stability condition.

\subsection{Variance decompositions (VDCs) and Impulse response functions}

We adapt variance decomposition to explain the magnitude of the forecast error variance determined by the shocks to each of the explanatory variables over time. The results are presented in Table 9.

Detecting Granger causality is strictly restricted to within-sample tests and does not show the relative magnitude of these variables. In order to estimate the degree of exogeneity of the variables, dynamic properties of the system, and the relative strength of the Granger-causal relationship beyond the sample period, we consider the decomposition of variance methodology. The variance decomposition method measures the percentage of a variable's forecast error variance that occurs as the result of a shock from each of the variables into contributions arising from its own and the other variables' variance. The results of variance decomposition for the three countries are summarized in Table 9 over a 20 -year period.

Based on the Korean data, the variance decomposing value of GDP and OPEN is almost the same level at the end of 6 year. After then, the variance of OPEN decreases rapidly. From $13^{\text {th }}$ year to $20^{\text {th }}$ year OPEN approximately accounted for $7 \%$ to the total variance. At the same time, GDPs share increase rapidly. Finally, at the end of 20 years, the forecast error variance for $\mathrm{CO} 2$, explained by its own innovations, is $25.75 \%$ and GDP represents $67.25 \%$ percent of the variance of $\mathrm{CO} 2$. In the short-run, OPEN considerably effects $\mathrm{CO} 2$ emission. This result coincides with the analysis of the coefficient of VECM. Furthermore, in the long-run, GDP absolutely influences CO2 emission. 
Table 9: Decomposition of Variance

\begin{tabular}{|c|c|c|c|c|c|c|c|c|c|c|c|c|}
\hline & \multicolumn{4}{|c|}{ China } & \multicolumn{4}{|c|}{ Korea } & \multicolumn{4}{|c|}{ Japan } \\
\hline Period & S.E. & $\mathrm{CO} 2$ & GDP & OPEN & S.E. & $\mathrm{CO} 2$ & GDP & OPEN & S.E. & $\mathrm{CO} 2$ & GDP & OPEN \\
\hline 1 & 11.41 & 100.00 & 0.00 & 0.00 & 12.12 & 100.00 & 0.00 & 0.00 & 0.046 & 100.00 & 0.00 & 0.00 \\
\hline 2 & 12.21 & 88.79 & 1.05 & 10.16 & 15.30 & 79.23 & 16.83 & 3.93 & 0.048 & 99.32 & 0.34 & 0.34 \\
\hline 3 & 14.21 & 74.26 & 13.35 & 12.39 & 15.65 & 75.69 & 20.09 & 4.22 & 0.055 & 97.84 & 1.16 & 1.00 \\
\hline 4 & 14.93 & 68.91 & 13.16 & 17.92 & 17.12 & 63.74 & 17.86 & 18.39 & 0.059 & 95.71 & 2.48 & 1.81 \\
\hline 5 & 14.98 & 68.43 & 13.23 & 18.34 & 17.91 & 58.51 & 16.75 & 24.74 & 0.062 & 93.13 & 4.25 & 2.63 \\
\hline 6 & 16.75 & 58.88 & 11.38 & 29.75 & 20.76 & 44.93 & 27.55 & 27.52 & 0.064 & 90.32 & 6.37 & 3.31 \\
\hline 7 & 22.05 & 34.97 & 8.68 & 56.36 & 25.93 & 31.06 & 51.17 & 17.76 & 0.065 & 87.53 & 8.70 & 3.77 \\
\hline 8 & 24.17 & 30.45 & 15.24 & 54.31 & 28.75 & 26.56 & 57.74 & 15.70 & 0.066 & 84.95 & 11.07 & 3.98 \\
\hline 9 & 27.12 & 24.80 & 31.45 & 43.75 & 31.64 & 23.10 & 63.84 & 13.07 & 0.067 & 82.70 & 13.31 & 3.99 \\
\hline 10 & 31.52 & 32.44 & 34.75 & 32.81 & 35.39 & 22.69 & 66.73 & 10.58 & 0.068 & 80.82 & 15.27 & 3.90 \\
\hline 11 & 35.45 & 39.55 & 33.82 & 26.64 & 39.37 & 24.05 & 66.63 & 9.32 & 0.069 & 79.28 & 16.90 & 3.83 \\
\hline 12 & 37.89 & 39.58 & 37.02 & 23.40 & 41.28 & 22.95 & 68.53 & 8.51 & 0.069 & 77.97 & 18.15 & 3.88 \\
\hline 13 & 39.81 & 36.00 & 42.65 & 21.35 & 43.26 & 22.41 & 69.75 & 7.84 & 0.070 & 76.81 & 19.05 & 4.14 \\
\hline 14 & 48.61 & 25.35 & 57.34 & 17.31 & 44.97 & 22.85 & 69.89 & 7.26 & 0.071 & 75.69 & 19.65 & 4.66 \\
\hline 15 & 56.75 & 18.83 & 67.27 & 13.90 & 45.51 & 22.46 & 70.36 & 7.18 & 0.072 & 74.56 & 20.00 & 5.43 \\
\hline 16 & 73.95 & 11.22 & 68.68 & 20.11 & 45.71 & 22.35 & 70.46 & 7.18 & 0.072 & 73.39 & 20.16 & 6.45 \\
\hline 17 & 93.39 & 7.04 & 70.16 & 22.79 & 45.94 & 22.41 & 70.36 & 7.23 & 0.073 & 72.18 & 20.17 & 7.64 \\
\hline 18 & 110.96 & 5.59 & 74.12 & 20.29 & 46.17 & 22.45 & 70.27 & 7.28 & 0.074 & 70.96 & 20.09 & 8.96 \\
\hline 19 & 134.95 & 4.28 & 75.99 & 19.73 & 46.53 & 23.59 & 69.24 & 7.17 & 0.074 & 69.75 & 19.93 & 10.32 \\
\hline 20 & 166.01 & 3.35 & 77.56 & 19.08 & 47.21 & 25.75 & 67.25 & 6.99 & 0.075 & 68.62 & 19.73 & 11.66 \\
\hline
\end{tabular}

In the case of China, at the first period, the forecast error variance for $\mathrm{CO} 2$ is perfectly explained by its own innovation. Interestingly, at the early part of the period, the forecast error variance of $\mathrm{CO} 2$ explained by its own innovation is $100.0 \%$ but the variance decomposition of results indicates that GDP and OPEN have a great influence as time elapses. For instance, at the end of 3 years, the direct effect of $\mathrm{CO} 2$ falls rapidly by as much as $74.26 \%$. Also notable is the fact that OPEN's share sharply increases and it accounted for 56.36 percent by seventh year. $\mathrm{CO} 2$ can be mainly explained by innovations in OPEN in the early stage. After that, the situation is reversed. Since the seventh year, the Table 9 shows a rapid rise in GDP from $8.68 \%$ to $77.56 \%$. At the end of 20 years the forecast error variance for $\mathrm{CO} 2$ explained by its own innovations is just $3.35 \%$ and other variables show higher percentage error variance in explaining CO2 variations. This result corresponds to Granger causality tests that GDP and OPEN Granger-cause $\mathrm{CO} 2$.

When the Japanese data is concerned, the forecast error variance for $\mathrm{CO} 2$ is considerably explained by its own innovation by $68.62 \%$ at the end of 20 years. GDP has an effect equal to twice as much as OPEN but these have a weaker influence on $\mathrm{CO} 2$ emissions after 20 years from the shocks. The difference of Japan's data is very marked indeed comparing Korea and China. Japan explains $69.0 \%$ of its own shocks.

In order to identify the impulse response, we impose an additional restriction on the VAR/VECM model. This paper uses the Choleski impulse functions. The impulse response functions are described in Figure 5. 
(a) Korea

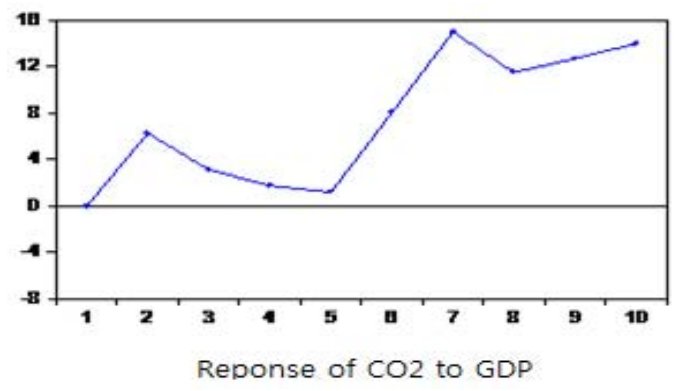

(b) China

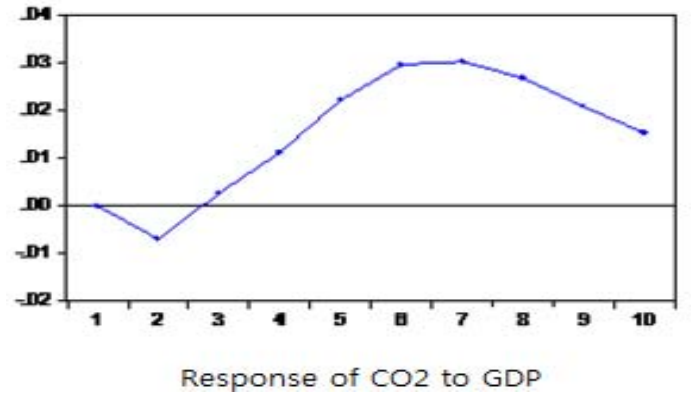

(c) Japan

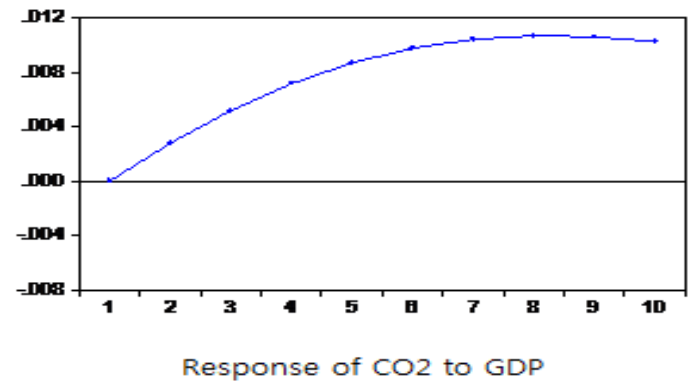

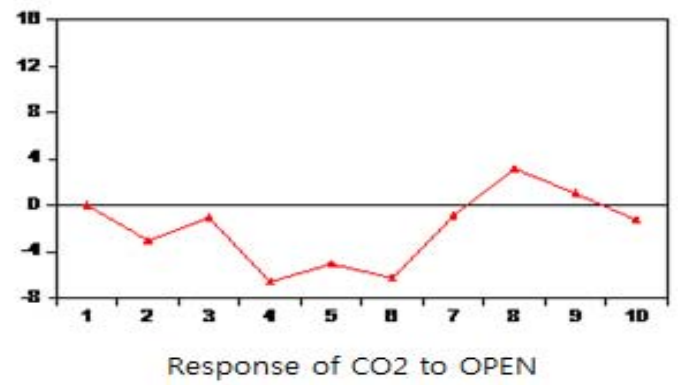
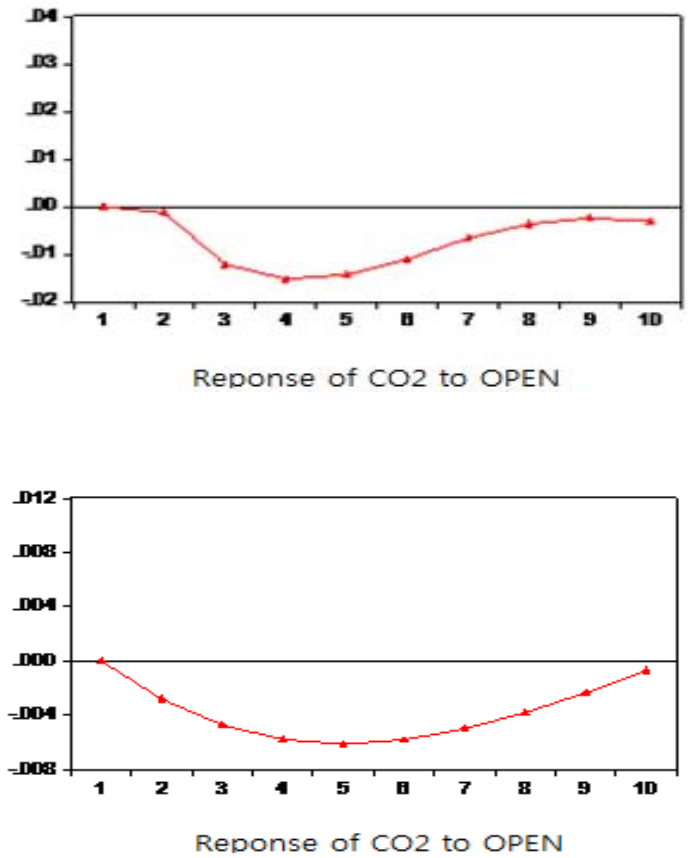

Figure 5: Response of Generalized one S.D. Innovation to GDP and OPEN

The graphs reported in Figure 5 show how much carbon dioxide would change in response to one standard deviation of innovation to GDP and OPEN in each country. First, in the Korean case, the response of innovation of $\mathrm{CO} 2$ to GDP increases until period 2. After then, during the period 2-5, it drops. The periods are 5-7, 7-8 and 8-10. During these periods the response to innovation repeatedly rises and falls. After all, the long-run relationship of $\mathrm{CO} 2$ and GDP is positive. This coincides with the previous results. Both in the short-run and long-run, the impact is not gone and this pattern is also similar to the response of innovation of $\mathrm{CO} 2$ to OPEN. In the early stage, it repeatedly rises and falls sensitively and at the same time, $\mathrm{CO} 2$ and OPEN maintain their negative relationships. This is in line with and corresponds closely to the previous results.

In looking at the response of $\mathrm{CO} 2$ to GDP, in case of China, we note that during the first two periods, these three variables have negative relationships and there would be a 
positive response after period 3. After the $7^{\text {th }}$ period, the increasing pattern is reversed but the positive relationship is maintained. $\mathrm{CO} 2$ and GDP have a positive relationship in the long-run and this coincides with the previous results as well. According to the response of $\mathrm{CO} 2$ to OPEN, since the first period, the relation of $\mathrm{CO} 2$ and OPEN is

found to be negative. However, from the $9^{\text {th }}$ period onwards, the shock wave abates till finally it dies away.

The response of $\mathrm{CO} 2$ to GDP and $\mathrm{CO} 2$ to OPEN has a very similar pattern but with the difference that the sign is opposite. These are reported in Figure 5. Japan's CO2 and GDP also have a positive long-run relationship. GDP and OPEN show a negative reaction but at the end of period, it vanishes.

\section{Conclusion}

Previous studies have provided a better understanding of the environmental consequences of economic growth and international trade. This paper addresses this topic in the context of China, Korea, and Japan, three main East Asian countries that reflect different levels of economic development. The paper takes into account the debate over the existence of the environmental Kuznets curve (EKC) and uses the econometric time series technique to develop VAR/VEC models. The results indicate the existence of dynamic relationships among the key variables of interest.

In this study we estimated the EKC by using annual time series data on $\mathrm{CO} 2$ emissions (1971 to 2006). The three countries showed considerable differences in the temporal patterns of environmental quality and the EKC. For Korea, there was no inverted Ushaped EKC. The EKC suggests that, if one country reaches a certain standard of economic growth, emissions would be reduced and thereby environmental conditions improved. We cannot find a declined area after reaching high economic growth to be consistent with the above hypothesis. We find a turning point at $\$ 8,210$ in the estimated result, but it represents U-shaped curve. Thus, it is difficult to conclude that this curve would show a decreasing trend after a new turning point.

China had an N-shaped Kuznets curve because the cubic model specification was statistically significant. This curve was initially an inverted U-shaped curve, but after the turning point, it rises again. Considering only the coefficient's signs, beyond a certain income level, $\mathrm{CO} 2$ emissions and income have a part representing a negative relationship. However, if we look at the Chinese EKC curve, it represents only an increasing trend.

For Japan, the inverted $\mathrm{N}$-shaped curve, which is unexpected, was statistically significant in terms of the relationship between GDP and CO2 emissions. In terms of $\mathrm{CO} 2$ emissions, there was no U-shaped EKC. These results suggest that economic growth is not the only way to improve the quality of the environment and that the resulting EKC hypothesis is inconclusive. The fact that Japan showed a decreasing trend in recent years is noteworthy.

We expected that $\mathrm{CO} 2$ emissions and free trade would have an inverted U-shaped relationship. However, if a country's income level is not high enough for it to care about the environment, then trade liberalization is likely to be an important factor influencing the deterioration of the quality of the environment. Thus, the level of a country's economic development had considerable influence on $\mathrm{CO} 2$ emissions and 
OPEN, which was the case for Korea. The relationship became negative when Korea reached the turning point. This suggests pollution is likely to decrease when the country becomes more open. For Korea, free trade may be an important solution to its environmental problems. The increased levels of income from free trade have elevated the country's standard of living, and the public is not only concerned about the quality of their environment but is also able to increase their consumption of environmental goods. These facts help explain the shape of Korea's EKC curve.

For China, there was a U-shaped curve. After the turning point, the quality of the country's environment worsened, and there was a positive relationship between openness and environmental quality. This can be explained as follow. Developing countries' markets pursuing a policy of openness tend to accept pollution-intensive industries to achieve a higher rate of economic growth. By contrast, developed countries typically apply strict environmental standards to attract eco-friendly industries. Therefore, when emerging markets engage in trade liberalization, they are likely to experience more pollution, which reflects China's situation. In addition, China's unique political and economic situation further explains its U-shaped curve. For Japan, the relationship between $\mathrm{CO} 2$ and OPEN was positive.

For Korea and China, $\mathrm{CO} 2$ emissions and GDP had a positive long-run relationship. However, $\mathrm{CO} 2$ emissions and OPEN had a negative short-run relationship for Korea. There was no significant short-run relationship between $\mathrm{CO} 2$ emissions and GDP. For China, CO2 emissions and GDP linkage had only a significant positive relationship. Thus, for China, economic growth increased $\mathrm{CO} 2$ emissions both in the short run and in the long run. As the result of variance decompositions and impulse response functions shows, the forecast error variance for $\mathrm{CO} 2$ explained by its own innovations is $25.7 \%$ at the end of 20 years for Korea and it is mostly influenced by GDP by up to $67.2 \%$. In contrast, OPEN is the least influential factor. The percentage of the variance in $\mathrm{CO} 2$ that can be explained by GDP is about $77.6 \%$ and OPEN about $19.1 \%$. CO2 explained by its own lag is only $3.0 \%$. Japan shows a clear distinction. The GDP share is $19.7 \%$ and the OPEN share is $11.7 \%$. However, after 20 years post shock, CO2 explains over $68.6 \%$ of its own shock. When compared with Korea and China, it is very remarkable.

Despite the notable findings, this study has some limitations. Most importantly, the sample size was too small. Access to data was limited, and only annual time series data on individual countries were available. The OLS method, short-run and long-run dynamic relationships, variance decomposition, and impulse response functions may provide different results if the data set is expanded to reflect quarterly or monthly series.

Korea, China, and Japan showed very different EKC patterns. Reducing CO2 emissions is not a legal requirement, and thus, each country tends to develop and implement environmental policies that reflect its own interests and typically establishes its own reduction goals. Further, it would be difficult to develop global measures and enforce them. Thus, voluntary efforts to improve the environment have thus far been the only realistic approach. The results suggest that $\mathrm{CO} 2$ emissions are likely to increase as the economy continues to expand. Thus, reducing $\mathrm{CO} 2$ emissions has become a critical global issue, and developing measures for reducing $\mathrm{CO} 2$ emissions has become an urgent task. However, rather developed countries, like Japan, have the possibility of being able to reduce $\mathrm{CO} 2$ emissions, although $\mathrm{CO} 2$ is not a local pollutant but a global 
one. Hence, $\mathrm{CO} 2$ emissions can be reduced by international cooperation. The results of this study are expected to be useful for providing a better understanding of the environmental problems and for identifying the ways in which the negative effects of $\mathrm{CO} 2$ emissions can be minimized. 


\section{References}

Akbostancı E., S. Türüt-Aşık and G. İpek-Tunç (2009), The relationship between income and environment in Turkey: Is there an environmental Kuznets curve? Energy Policy 37, 861-867.

Al-Amin, Hossain E., Siwar C. and A. Hamid (2007), Trade, economic development and the environment: Bangladeshi perspective. Social Science Research Network, http://ssrn.com/abstract=1013247.

Azomahou T., Laisney F. and P.N. Van (2006), Economic development and CO2 emissions: A nonparametric panel approach, Journal of Public Economics 90, 1347-1363.

Baek J.H, Y.S. Cho and W.W. Koo (2009), The environmental consequences of globalization: A country-specific time-series analysis, Ecological Economics 68, 2255-2264.

Bradford D.F., R. Schlieckert and S.H. Shore (2005), The Environmental Kuznets Curve: Exploring a Fresh Specification, Economic Analysis \& Policy 4(1), Article 5.

Cole, M.A., A.J. Rayner and J.M. Bates (1997), The environmental Kuznets Curve: and empirical analysis, Environmental and Development Economics 2, 401-416.

Copeland B.R. and M.S. Taylor (1994), North-South trade and the environment. Quarterly Journal of Economics 109(3), 755-787.

Copeland B.R. and M.S. Taylor (2004), Trade, growth, and the environment, Journal of Economic Literature 42(1), 7-71.

Dasgupta S., B. Laplante, H. Wang and D. Wheeler (2002), Confronting the Environmental Kuznets Curve, Journal of Economic Perspective 16(1), 147-168.

Dickey D.A. and W.A. Fuller (1979), Distribution of the Estimators for Autoregressive Time Series with a Unit Root, Journal of the American Statistical Association 74, 427-431.

Dickey D.A. and W.A. Fuller (1981), Likelihood Ratio Statistics for Autoregressive Time Series with a Unit Root, Econometrica 49, 1057-1072.

Dietz S. (2000), Does an Environmental Kuznets curve Exist for Biodiversity?, Institut für Wirtschaftsforschung, Eidgenössische Technische Hochschule Zürich.

Ekins P. (2000), Economic growth and environmental sustainability: the prospects for growth, London, Routledge.

Eakin H. and S.T. Seldon (1995), Stoking the Fires? CO2 Emission and Economic Growth, Journal of Public Economic 57, 85-101.

Engle R. and C.W.J. Granger (1987), Cointegration and Error Correction: Representation, Estimation and Testing, Econometrica 55, 251-276.

Esty D. and D. Giradin (1998), Environmental Protection and International Competitiveness: A Conceptual Framework, Journal of World Trade 32( 3), 5-46.

Friedl B. and M. Getzner (2003), Determinants of CO2 emissions in a small open economy, Ecological Economics 45, 133-148.

Galeotti, M. (2003), Economic Growth and the Quality of the Environment: Taking Stock, Fondazione Eni Enrico Mattei Working Paper N.89.2003.

Galeotti M. and A. Lanza (1999), Richer and cleaner? A study on carbon dioxide emissions in developing countries, Energy Policy 27, 565- 573.

Galeotti, M. and A. Lanza (2005), Desperately Seeking (Environmental) Kuznets, Environmental Modelling and Software, 20, 1379-1388. 
Galeotti, M., A. Lanza and F. Pauli (2006), Reassessing the Environmental Kuznets curve for CO2 Emissions: A Robustness Exercise, Ecological Economics 57, 152163.

Galeotti M., M. Manera and A. Lanza (2009), On the Robustness of Robustness Checks of the Environmental Kuznets curve Hypothesis, Environmental and Resource Economics 42, 551-574.

Grossman G.M. and A.B. Krueger (1991), Environmental impacts of a North American Free Trade Agreement, NBER working Paper Series, 3914.

Grossman G.M. and A.B. Krueger (1993), Environmental impacts of the North American Free Trade Agreement, in Peter Garber (Ed.), The U.S.-Mexico Free Trade Agreement. MIT Press, Cambridge.

Grossman G.M. and A.B. Krueger (1995), Economic Growth and Environment, Quarterly Journal of Economic 60, 353-377.

Grubb M., Butler L. and O. Feldman (2006), Analysis of the relationship between growth in Carbon Dioxide emissions and growth in Income. UK, Faculty of Economics, University of Cambridge.

Harris R. and R. Sollis (2003), Applied Time Series Modeling and Forecasting, Halsted Press.

Helpman E. (1988), Growth, Technological Progress, and Trade. National Bureau of Economic Research (Reprint No. 1145.).

Heshmati A. (2006), Conditional and Unconditional Inequality and Growth Relationships, Applied Economics Letters 13, 925-931.

Heston, A., R. Summers and B. Aten (2009). Penn World Table Version 6.3, Center for International Comparisons of Production, Income and Prices at the University of Pennsylvania, August 2009.

Hettige H., M. Mani and D. Wheeler (2000), Industrial Pollution in Economic Development: The Environmental Kuznets curve Revisited, Journal of Development Economics 62, 445-476.

Holtz-Eakin D. and T.M. Selden (1995), Stoking the fires? CO2 Emissions and Economic Growth, Journal of Public Economics 57, 85-101.

Huang W.M, G.W.M. Lee and C.C. Wu (2008), GHG emissions, GDP growth and the Kyoto protocol: a revisit of Environmental Kuznets curve hypothesis, Energy Policy 36, 239-47.

Johansen S. (1988), Statistical Analysis of Cointegrating Vectors. Journal of Economic Dynamic and Control 12, 231-254.

Johansen S. (1995), Likelihood-based inference in cointegrated vector autoregressive models. Oxford: Oxford University Press.

Johansen S. and K. Juselius (1990), Maximum Likelihood Estimation and Inference on Cointegration-with Applications to the Demand for Money. Oxford Bulletin of Economics and Statistics 52, 169-210.

Johansen S. and K. Juselius (1992), Testing Structural Hypotheses in a Multivariate Cointegration Analysis of the PPP and the UIP for UK, Journal of Econometrics 53(1-3), 211-244.

Kuznets S. (1955), Economic Growth and income inequality, American Economic Review 45(1), 1-28.

Kuznets S. (1979), Growth, Population and Income Distribution, Selected Essays, New York: Norton. 
List J.A. and C.A. Gallet (1999), The environmental Kuznets curve: does one size fit all?, Ecological Economics 31, 409-423.

Munasinghe M. (1995), Making economic growth more sustainable. Ecological Economics 15, 121-124.

Munasinghe M. (1999), Is environmental degradation an inevitable consequence of economic growth: tunneling through the environmental Kuznets curve, Ecological Economics 29, 89-109.

Moomaw W.R. and G.C. Unruh (1997), Are environmental Kuznets curves misleading us? The case of $\mathrm{CO} 2$ emissions, Environment and Development Economics 2, 451463.

Seldon T.M. and D. Song (1994), Environmental Quality and Development: Is There a Kuznets Curve for Air Pollution Emissions?, Journal of Environmental Economics And Management 27, 147-162.

Taskin F. and O. Zaim (2000), Searching for a Kuznets Curve in Environmental Efficiency, Using Kernel Estimation, Economics Letters 68, 217-223.

Torras M. and J.K. Boyce (1998), Income, Inequality, and Pollution: A Reassessment of the Environmental Kuznets Curve, Ecological Economics 25(2),147-160

Unruh G.C. and W.R. Moomaw (1998), An alternative analysis of apparent EKC-type transitions, Ecological Economics 25, 221-229. 